\title{
Del significado de algunos términos usados en los documentos de la revolución tupamarista, $1780 \cdot 1783$
}

\section{Jan Szeminski}

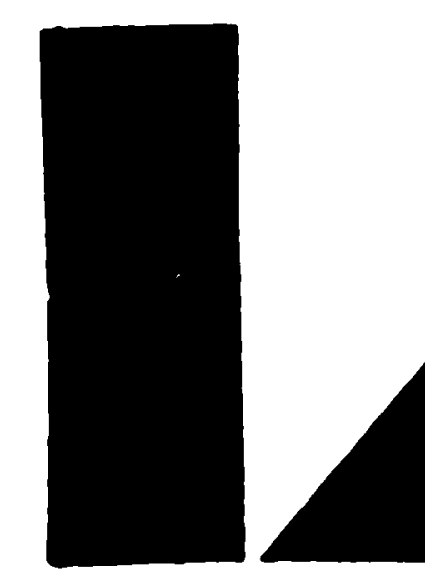

a guerra civil es la forma más drástica de conflicto social y por lo tanto es de esperar, que en los documentos surgidos en relación con ella, el reflejo de las diferencias sociales percibidas por sus participantes sea el más completo. Ya en 1972, formulé una hipótesis acerca de la coexistencia de cuatro jerarquías paralelas ${ }^{1}$, jerarquías de castas, estamentos, culturas y de clases (capas sociales). Se supone, que los niveles de las cuatro jerarquías eran denominados de forma similar, o aun de igual manera, y por lo tanto se puede reconocer la existencia de varias jerarquías solamente cuando una y la misma persona es denominada simultáneamente con términos distintos, e.g.: hacendado, indio, español, cholo.

En primer lugar, con el objeto de buscar en las fuentes pruebas de la existencia de varias jerarquías, he escogido aquellos fragmentos, en los cuales se muestran las diferencias de una jerarquía en relación con las restantes, para luego continuar con la distinción y diferenciación de niveles. A continuación, en base a aquellos fragmentos que hube de reconocer como reflejo de una jerarquía dada, califiqué la importancia de sus niveles (entre más importante sea un nivel, más veces será mencionado) y su composición. Este procedimiento fue repetido cuatro veces por separado, una vez para cada una de las jerarquías.

Las fuentes de las que dispuse servían más bien, para investigar las opiniones, la percepción de las jerarquías sociales, puesto que corresponden a un corto período de tiempo y provienen de los relativamente homogéneos sur del Bajo Perú y del Alto Perú. No son ellas el producto de un solo grupo de gente, sino de los repre- 
sentantes de diversos grupos socialés, tanto de rebeldes como de contrarios a la insurrección.

En el transcurso del trabajo he utilizado sobre todo,'la Colección Documental de la Independencia del Perú, Tomo II; La Rebelión de Túpac Amaru, vol. 1-4, así, como los documentos publicados en los trabajos de Boleslao Lewin, Jorge Cornejo Bouroncle y otros. De mucha ayuda me fueron igualmente, algunos materiales de archivo. Tuve la posibilidad de leerlos en los archivos y bibliotecas de Lima, Cusco y Arequipa en 1974, gracias a una beca del Consejo Nacional de la Universidad Peruana.

\section{DE LAS CASTAS}

En 27 documentos de diferentes autores, entre otros de rebeldes, ine hallado fragmentos en los cuales aparece un contraste entre los . ombres probablemente relativos a la jerarquía de castas y los niveles de otras jerarquías (véase la Tabla 1). Como resulta de la información en ellos contenida. los nombres que parecen corresponder a los de las castas se contraponen a aquellos términos que indudablemente se refieren a otras divisiones sociales. Lintre aquellos tẹrminos que a primera vista parecen estar vinculados a la jerarquía de castas, tenemos: espalioles, mestizos, indios, cholos, zambos, negros, gente blanca, castas, criollos, naturales, blancos.

Sus contrarios son aquellas palabras que sugieren obligaciones y ?rivilegios estamentales: cacique, nobles, principales, tributarios, forasteros, naturales, patricios, españoles; aquellas que claramente se refieren a la cultura: los que tienen camisa, ladinos, españoles; a la filación "étnica": criollo, americano, indio; así, como a la filiación social o grupo profesional: arriero, ministro, tributario, indio, forastero, cacique, plebe, vulgo, comerciante, etc.

i erece un comentario aparte aquella expresión de una de las declaraciones de Tilupa Catari (Julián Apasa), que dice: "indios de collana"2. Permite ella diferenciar aquellos indios que no eran collana, de aquellos collana que no eran indios. El término "collana, correctamente qullana, proveniente de una clasificación social y de un sistema de parentesco aún anterior a Pizarro y que pasó a la lengua española como principales. Indica él, que pudo 
existir una clasificación social, jerarquía, que encontró en las fuentes un escaso reflejo.

Los casos mencionados de contraste de los términos de otras jerarquías con aquellos de la de castas, casi en su totalidad provienen de documentos que no son el producto de la pluma de los insurrectos. Tan sólo dos de ellos son obra de participantes en la insurrección, los otros son declaraciones y documentos anteriores, o hechos para dialogar con las autoridades españolas.

Puesto que hemos demostrado la existencia de una jerarquía de castas distinta de las otras jerarquías sociales, intentemos ahora, ver cuales eran sus criterios de clasificación.

Se pueden encontrar entre los abundantes documentos, aquellos fragmentos relativos a los criterios de clasificación en una ú otra casta así, como qué castas se consideraban y qué relaciones había entre ellas.

El 27 de febrero de 1780, en el Cusco, el capellán Simón Ximicenez Villalva escribe, que los criollos nos odian, es decir "a nosotros" los españoles, compara a los criollos con los indios y contrapone americanos a españoles ${ }^{3}$.

La "Relación del más orrendo atentado que cometió J. G. Thupa Amaro" menciona a los "criollos americanos de todas clases así españoles como líestizos e Yindios", los que opone a los europeos.

La "Relación de la derróta lamentable", del 20 de noviembre de 1780 , en Quispicanchi, contrapone "españoles criollos" a "españoles europeos" 5 :

El virrey de Buenos Aire, en oficio al Ministro de Indias usa la expresión "mestizos y otras castas"6.

El Obispo del Cusco escribe a Lima sobre "mestizos y otras castas" o sobre "mestizos y otras mezclas"8.

En el bando publicado para exhortar a los indios de todas las provincias el que no presten auxilio al rebelde J.G: Thupa Amaro, las autoridades del virreinato lo llaman "indio" y hablan de "otras castas"9. 
El Obispo del Cusco en otra carta al virrey escribe sobre "gente blanca"10.

El autor de un diario de Arequipa describe a "españoles y mestizos. ..., dos hombres rubios y de buen aspecto, que le parecieron ingleses" 11 -

La "Relación de las alternaciones de los Pueblos de las Quebradas inmediatas a la ciudad del Cusco" describe a "un mestizo orrendo en fealdad con el labio dividido en tres partes que parece un dragón, que tuvo ánimo para antes y después de matar a una infeliz muger blanca, a su marido, y a sus hijos, usar de ella carnalmente dentro de la Yglesia del dhO Calca"12.

En la descripción de los "acaecimientos ocurridos en el pueblo de Challapata" aparecen: un chapetón, Don Miguel de Figueroa Arequipeño y algunos criollos, mestizos y cholos $^{13}$.

Mateo Urvicaín menciona a mestizos, zambos, negros e indios, así, como a europeos y $\operatorname{cholos}^{14}$, y en otro lugar "iombres de' varias castas y los más indios" 15 .

En la "relación de los horribles estragos que en el 10 de febrero de 1781 hicieron los cholos e yndios patricios en Oruro" encontramos: cholos, zambos, indios, criollos, chapetones, y negros ${ }^{16}$ -

En la descripción de la insurrección en las provincias de Larecaja y Cochabamba se encuentra el siguiente aparte: "En Tapacari mataron con mayor crueldad a todos los que tenían cara blanca sin distinción de sexos. A los muchachos españolitos y mestizos los subían a las torres, y de alli los precipitaban"17.

A Dámaso Catari, durante los interrogatorios se le preguntó, si alguien le había aconsejado matar a la "gente blanca" y expresamente a los chapetones ${ }^{18}$.

El procurador de la villa de Oruro afirmó, que los naturales te$m$ ían que los españoles quisieran matarles ${ }^{19}$.

Según J.A. de Areche los "indios" y "otras castas" de la plebe" odiaban a "todo europeo o a toda cara blanca o pucacuncas" (puka kunka) ${ }^{20}$.

J.G. Thupa Amaro en sus declaraciones describe a cierto hom- 
bre como español de Ica, quien en realidad era "mestizo blanco de pelo rubio y ojos azules" 21 .

Eusebio Balza de Berganza describe le genealogía de cierto sacerdote: "el padre del clérigo Puente fue un herrero, cuarentón,. . . y su madre. . . requinterona" 22 .

D. C. Thupa Amaro, en bando del 29 de agosto de 1781, en el cual abolió la esclavitud, aclara que "los esclavos, negros, sambos, mulatos cuando se usan muy maltratados de sus amos. . . se vendrán los dichos esclavos a éste mi Real Cabildo, y no conocerán a 'dichos sus amos"23. El mismo, en un informe dirigido al virrey afirma, que "los corregidores vienen a chupar y aprovechar la sangre y sudor de los españoles y naturales del Perú" ${ }^{24}$.

Evidentemente, tal enumeración de ejemplos se puede continuar ad aeternum. Sin embargo, de ellos se concluye, que la jerarquía de castas era conocida y que era ésta una clasificación de los individuos según el lugar de origen de sus antepasados y el lugar de nacimiento propio. Se podía nacer en el Perú o en España (otros lugares de nacimiento eran tan poco frecuentes, que no hay necesidad de tenerlos en cuenta). Los antepasados podían provenir de España, el Perú o bien de Africa.

En la práctica, el criterio del lugar de nacimiento se refería sola y exclusivamente a la distinción entre aquellos individuos nacidos en Europa, es decir en España y el resto, es decir en el Perú. Estos a su vez, sustituyeron la clasificación según la proveniencia de los antepasados, por otra según la apariencia, esto es, según el color de la piel, del cabello, de los ojos, carencia de barba, etc. De acuerdo con esta clasificación se pueden mencionar las siguientes categorías: europeo, llamado también, español europeo o simplemente español; criollo, llamado también, español americano, español criollo; mestizo, cholo; indio; negro; sambo, zambo, zambaigo; mulato llamado también, pardo, mulatillo; y una diferenciación más detallada como quinterón, requinterón, que sólo se refiere a aquellas castas producto de la unión de españoles y negros.

Para los españoles y a veces también para los mestizos se empleaba la expresión "gente blanca", o sencillamente "blancos", llamados por los indígenas puka kunka (cuellos rojos). Para los 
indios, cholos y a menudo también para los mestizos y aun criollos, se encuentra también el término "naturales".

La discusión acerca de la diferenciación de privilegios y derechos de las diferentes castas será desarrollada más adelante, ya que la definición de los derechos, por ejemplo, de los indios no aclara si se trata de la casta o del estamento "indios".

\section{DE LOS ESTAMENTOS}

La jerarquía de castas puede ser percibida y descrita con bastante facilidad: al fin y al cabo es sabido, que los españoles conquistaron el Perú, introdujeron a los negros, se acostaron con las indias y las negras y otorgaron determinadas obligaciones y privilegios a los diferentes grupos de la población. Los indios (como casta) debian pagar un tributo y servir trabajando en la mita, aunque algunos de ellos estuvicran eximidos de tales cargas. A los mestizos se les prohibía cohabitar con los aborígenes (lo mismo que a los españoles y en general a los no indigenas). Los españoles tenian derecho a gobernar, gobernaron y desempeitaron los cargos oficiales.

Los estamentos han sido causa del problema tanto para los españoles. como para los investigadores contemporáneos. Como es sabido de otras filentes. los espanoles que atravésaban el Atlántico. se dividian en nobles y no-nobles, o más exactamente, en clérigos, nobleza dividida en varios grupos y otros. En el Perú hallaron una compleja estructura social, algunos rasgos de la cual eran similares a los de las europeas, y por lo tanto a las divisiones estamentales españolas. in consecuencia, los conquistadores, al menos parcialmente, identificaron algunas de las divisiones sociales hereditarias ilalladas en el Perú, con las europeas ya conocidas. Sin embargo. debió existir también el proceso contrario, de identificación por parte de los conquistados, de las divisiones sociales conocidas por los españoles como estamentos, con algunas de las propias ${ }^{25}$.

La jerarcuía estamental tenía como principio un privilegio $u$ obligación hereditaria, de una manera semejante a la jerarquía de castas. Ambas permitían los matrimonios por encima de las diferencias de castas en un caso, y de estamentos en el otro, lo que hace preguntarse a qué grupo debería pertenecer la prole. En la 
jerarquía de castas la respuesta es obvia, el descendiente pertenecerá a la tercera casta, si los padres provienen de dos distintas; en la jerarquía estamental española, por el contrario, se heredaba la pertenencia a un grupo por línea paterna, y en aquella del Tawantinsuyu por ambas líneas, teniendo en cuenta algunos otros factores adicionales.

Para verificar si tanto en el sur del Bajo Perú, como en el Alto, se distinguían en general los estamentos, he recogido toda contraposición entre los términos que creí de carácter estamental y aquellos que indicaban otras divisiones sociales. (Véase la Tabla 2).

La Tabla 2 exige evidentemente, algunos comentarios. Como la mayor parte de ella se refiere igualmente a aquellas expresiones que muestran los diferentes niveles de la jerarquía estamental, los comentarios acerca de ella han sido agregados a las consideraciones acerca de los dichos niveles, es decir, sobre los estamentos distinguidos por los autores de las fuentes, o por los entonces habitantes del sur del Perú. A jrimera vista, de la tabla se concluyen dos cosas: se percibían estamentos, especialmente aquellos de la nobleza y los esclavos. Sin embargo, al mismo tiempo se ve, al nienos en la terminología, una mezcla de estamentos y castas, o también una tendencia a iclentificar las jerarquías de castas y estamentos.

El Obispo del Cusco se quejó al visitador J.A. de Areche, que J. G. Thupa Amaro "no hacía distinción de clases, castas, edades ni estados"26. J. G. Thupa Amaro, también en carta a J.A. de Areche usa la expresión "todos los provincianos de todos estados" y los excesos cometidos por los corregidores eran aclarados con la afirmación de que son "de cunas muy bajas" 28 . Tanto el obispo como el jefe de la insurrección se daban cuenta de la existencia de una jerarquía estamental. No resulta de esto, que los estamentos peruanos hay an sido identificados con los europeos, aunque tuviesen un rasgo en común: el ser hereditarios.

La Tabla 3 es el resultado de la búsqueda de los términos que designan los niveles en la jerarquía estamental. Al lado de cada término frecuente he colocado los sinónimos que raramente aparecen. 
Como se ve en la Tabla, los sinónimos de "noble" eran: Español, blanco, chapetón, patricio, lo que evidentemente resulta del alto status de casta de estos términos, que precisamente son utilizados por esto como sinónimos de "noble" y sugieren simultáneamente una contraposición a otros términos de casta empleados en un sentido estamental. El predominio del término "noble" sobre otros, si tuviésemos como prueba suficiente un número casual de expresiones ocasionalmente tomadas de fuentes casuales, resulta tal vez porque designa inequívocamente a la nobleza; no se confunde con los términos de la jerarquía de castas. De aquí, sus muy frecuentes apariciones en relación con indio. Indio noble es el título inequívoco del hidalgo indígena. Inka y nusta eran títulos aristocráticos ya antes de la conquista. El que aparezcan para designar a la crema y nata de la aristocracia indígena resulta natural y evidente.

Los sinónimos del término "indio", que ya conocemos en la jerarquía de castas aclaran y de alguna manera evitan el confundirlo con los términos de la jerarquía de castas. Tributario es aquel que paga un tributo. Aquel que está obligado a servir trabajando en la mita, es designado con el término "mitayo" (mit'ayuq). Los términos "originario" y "ordinario" distinguen en este caso sin importar cual sea el estamento, o inicialmente la casta para éstos, que son también "naturales", es decir aborígenes, por generaciones miembros de la comunidad y que tienen derecho total a la tierra y a prestar servicio, y para aquellos que tales derechos no tienen. Eran ellos "gente flotante" de diferentes nimo de este término era yanacona (del quechua yana- siervo, yanakuna- siervos). Seguramente a ellos también se refería el término "jornalero voluntario".

Sin embargo, esta gente no puede ser clasificada en la jerarquía estamental, son precisamente "gente flotante".

Términos como "hombre bajo" y "hombre de cuna baja" indican tan sólo la existencia de diferencias estamentales, designan a aquellos que no hacían parte de la nobleza. Para lo cual sirven también expresiones tales como: vulgo, plebeyo o pueblo.

El clero es evidentemente distinguido por el mismo hecho de ser sacerdote. Los esclavos tienen solamente un sinónimo: Negro. No 
resulta tampoco extraño, que no haya nombre alguno que corresponda a los libertos. En el sur del Bajo Perú y en el Alto Perú, tal grupo propiamente dicho no hubo. Encontré a un "zambo libre", pero no se puede concluir de aquí, que haya sido liberto.

El que se carezca de una expresión para designar a los individuos libres, que no son indios (tributarios) y no son nobles, nos hace reflexionar. Puede ser, que una parte de ellos se incluya en los términos que designan a la "gente flotante", por ejemplo: "forasteros". El grupo que a ellos corresponde es designado por algunos términos prestados de la jerarquía de castas: mestizo, cholo, zambo, o en general hombre de casta. Esta división en por lo menos tres grupos corresponde, simultáneamente a la genealogía de todos los tres: mestizo es el más estrechamente relacionado con noble y español; zambo es el descendiente negro-indígena, por lo común libre, proveniente de una comunidad esclava y campesina. Por último, cholo que es evidentemente un indio, que ha dejado de ser tributario.

Dos de los términos que figuran en la lista requieren una consideración especial: cacique y principal. El término "cacique" corresponde exactamente a kuraka, término muy difundido en el Perú $^{29}$. El kuraka o cacique era durante la conquista un noble hereditario indígena, claro está, situado en un nivel inferior al de los Incas, puesto que por lo común provenía de la aristocracia local. En las fuentes aquí utilizadas, cacique aparece como noble, pero no todo cacique lo es. Al mismo tiempo, el cacique está obligado a realizar diversas actividades: recaudación de impuestos, administración del campo o de la comunidad rural. Diversos bienes resultan relacionados con el cacicazgo. Quizás sería mejor incluir al cacique del siglo XVIII en la jerarquía de clases (estrato social). Es él un individuo con determinada función y status social, y no necesariamente un hidalgo.

Un término aún más inquietante resulta ser "principal". Algunas veces es éste el calificativo del cacique, puesto que en el pueblo, en la comunidad, había más de uno. A veces, puede ser que más frecuentemente aparezcan "cacique" y "principales", en plural, uno junto al otro; los principales son los representantes de la comunidad. Las decisiones pueden ser tomadas por los caciques, los principales y el común. 
Así como el término "cacique" corresponde al ya mencionado, pero no existente en las fuentes aquí empleadas, "kuraka", el término "principal" es hasta hoy día traducido al quechua como "qullana". Este, en cambio, resulta ser uno de los términos básicos de la organización social del siglo XVI en el Tawantinsuyu, significando en la concepción española: principales, nobleza inferior, grupo del cual salen los caciques ${ }^{30}$. En todo caso, ambos grupos de la nobleza menor indígena muy claramente se distinguen de "noble".

No deja de constituir un problema, el que en la jerarquía estamental aparezcan precisamente todos los términos empleados en la jerarquía de castas: español, indio, mestizo, cholo, negro, sambo, hombre de casta. El que falte en esta lista "criollo", se debe seguramente a que la muestra es demasiado pequeña y a la clara difusión del término "español" en el sentido que se puede esperar del estamental "criollo-noble".

$\mathrm{S}_{1}$ se considerase tan sólo la relación recíproca de estas jerarquías, sería posible o bien dividir cada casta en estamentos, o bien cada estamento en castas. Sin embargo, en expresiones tales como: "indio originario", "indio forastero", "español forastero", etc. no se sabe qué término se refiere a la casta, o si el término, por ejemplo, "indio" se refiere a la casta o al estamento.

De aquí, surgen cosas tales como el incluir a los indios en el grupo de los cholos. Probablemente se trate aquí, de los indios que han sido eximidos del tributo pero. ¿Se les ha eximido por ser aquellos miembros del estamento, que pertenecían a la casta, "cholos", o también por ser aquellos miembros de la casta, que pertenecían al estamento "cholos", o por último, ¿por haber avanzado de una casta a otra, o de un estamento a otro?. Las dos últimas posibilidades, considerando la pertenencia hereditaria a un estamento o casta, parecen ser absurdas. Sin embargo, lo más probable resulta ser, que las mismas reflexiones sobre el particular sean absurdas y carentes de sentido, ya que en realidad a nadie le importaba si se hablaba de casta o estamento. Lo esencial, desde el punto de vista del gobierno, es que resulta mejor que todos fuesen "indios"; desde el punto de vista de los interesados, resulta mejor ser evidentemente "cholos", puesto que los primeros pagan un tributo y deben laborar en la mita, y los segundos ni tributan ni mitan. 
El autor de uno de los documentos escribe, que los habitantes de Arequipa sabían, que el corregidor Semanat "se hallaba con orden del señor. . . Areche, para revisar personalmente a los indios naturales y forasteros y empadronar a los zambos, cholos y nestizos, para que todos pagasen tributo" ${ }^{31}$. De lo anterior resulta, que se trataba de abarcar a todos aquellos que no fueran campesinos. De esta misma fuente se concluye, que los mestizos estaban muy indignados, ya que como mestizos se tenían por nobles, lo que confirmaría el sentido estamental del término.

Haciendo un paréntesis, se puede decir, que las Leyes de Indias eximían del tributo a los menores de edad, viudas, ausentes así como a una parte de la nobleza, pero fuera de los mencionados, obligaba a todos los miembros de la casta ind ígena a pagarlo. Sin embargo, no resulta esto esencial para nuestras consideraciones. Es importante, el que los términos de la jerarquía de castas tengan a menudo un significado estamental ${ }^{32}$

\section{DE LAS CLASES Y ESTRATOS SOCIALES}

Ya durante la discusión acerca de los estamentos y las castas surgió el problema de si algunos de estos términos, o de los grupos por ellos designados, se refieren o no a grupos caracterizados con criterios de clase: disposición sobre los medios de producción, el producto y el excedente. Cuando me di a la búsqueda de aquellos fragmentos que pudieran referirse a la división en clases, o mejor aún, que pudiesen designar, de acuerdo a la intención de los autores de las fuentes, aquella que hoy denominamos división en clases resultó, que no hay cómo ordenarlos en grupos, en los cuales aparezcan claramente las contradicciones entre aquellos términos que se refieren a la división en clases y los restantses. En las descripciones de los conflictos aparecen tan sólo términos de castas $\mathrm{y}$ estamentos, por lo general no se sabe si con un significado estamental o de casta.

En tal situación, resulta necesario discutir cada uno de los fragmentos, que por informar probablemente acerca de la percepción de las diferencias entre las clases sociales hubiese yo seleccionado. Los diversos fragmentos fueron clasificados por autores, comen- 
zando por los conspiradores, insurrectos y presos, para luego considerar a los restantes, por lo general obra de funcionarios públicos.

El día 7 de enero de 1781 , en el Cusco, que estaba sitiado por los rebeldes, alguien colocó un pasquín intitulado: Testamento del Reparto Peruano. En él se encuentra las siguientes formulaciones:

"Item declaro que soy casado. . . con doña codicia de todas las cosas. . . y procreamos por nuestros hijos legítimos muchos condes, marqueses, caballeros del hábito de Santiago, ricos hombres y personas muy distinguidas. . . Item declaro que mis herederos no deben preguntar por mis calzones de lienzo ni calcetas, pues no habiéndolos usado en España, excuse como superfluo el gasto de ellos en este Reino del Perú... Item mando que a mis ayudantes, los seiiores directores de Lima y obrajeros de este Reino, se les pague lo que se les debe. . . de lo que hubiese dejado en ser y no hubiese robado en las provincias el fascineroso de Thupa Amaro, y si no se hallasen dichos bienes, y no supiesen cobrar de los vecinos, me lo perdonen. Es mi voluntad que por via de restitución todo lo que se saca de los corregidores para auxilio de la guerra se emplee en los sueldos de los miserables provincianos y en bien de las bodegoneras, pulperas, chicheras y oficiales pobres, siendo justo que tengan esta recompensa cuando ni aquellos comían por pagar el repartimiento, ni éstos por la misma causa sacaban utilidad de sus granjerías. . Item mando que dichos corregidores, obrajeros y otros mil interesados en los repartimientos paguen el doble desde ahora en adelante a los comerciantes, artesanos y demás oficiales que por causa del alzamiento ocasionado por ellos han dejado de trabajar todo el tiempo de la guerra. . . Item mando que por espacio de dos años vistan luto todos los que han sido y son los corregidores, mercaderes y particulares obrajeros y chorrilleros, y todos los demás fomentadores mios, sus mujeres e hijos, por ser muy de razón demuestren su sentimiento por la muerte del padre que los ha sacado de nada. . ."33.

En este texto aparece la división en pobres y ricos, pero también, lo que es significativamente más importante, aquella en ligados con el reparto (corregidores, mercaderes, obrajeros, chorri- 
lleros y otros) y afectados por él (campesinos y un grupo que a falta de mejor expresión, he dado en llamar "burguesía"). Ninguno de estos grupos tiene nombre propio, sin embargo, todos son designados por enumeración de tareas y empresas de las que son propietarios. Por último, se ve aquí también, la división entre la metrópoli de ultramar (España), la metrópoli local (Lima) y el explotado interior.

El 14 de abril de 1780 rindió declaración Ildefonso del Castillo, uno de los conspiradores del Cusco arrestados a comienzos de abril. I. del Castillo, administrador del taller (chorrillo) y de la hacienda Paucarpata confesó, que había conversado con otro conspirador sobre, que a causa de la nueva reglamentación tributaria "se enriquecen los chapetones y se llevaban todo el dinero. . . y sólo ellos comerciaban y gobernaban en tanto grado que ni aun alcaldes ordinarios querían hacer a los criollos" "34. En esta declaración sólo se contrapone a los españoles (de España), los locales.

Resulta bastante curioso el lamento de otro de los participantes en esta conspiración, Bernardo Tambohuacso, cacique de P'isaq, quien al declarar el 10 de julio de 1780 en el Cusco, se refirió a su conversación con otro de los conspiradores. El cacique, llamado al comienzo de la declaración "indio noble", dijo: "¿Para qué me mete Ud. con estos cholos?"35. Aquellos cholos son unos maestros plateros, indudablemente reconocidos como no-indígenas, "cholos" designa entonces, el estamento o la casta, o la clase, aunque pudo significar las tres cosas a la vez.

J. G. Thupa Amaro escribe en una carta al clérigo Gregorio Mariano Sánchez, que "los corregidores infieren insoportables trabajos a los indios con sus indebidos repartos"36. En el Cusco, el Inca declaró, que "él era Thupa Amaro, y que assí como el dueño de una hacienda se daba a conocer con sus jornaleros por lo que hazía, él quiso que sus paysanos biesen lo que hizo por ellos",37 .

De aquí se puede pensar, que J.G. Thupa Amaro distinguía dos grupos de gente: Trabajadores y hacendados, o mejor aún, propietarios de haciendas, los que equipara a la aristocracia, indudablemente hereditaria.

El hermano de J.G. Thupa Amaro, Diego Cristóbal Thupa Amaro, escribió al Virrey de Lima el 18 de octubre desde Azán- 
garo, ya durante las conversaciones de paz, repitiendo por lo demás, los mismos argumentos de su hermano: "Mi hermano jamás había intentado perjudicar ni agraviar a los españoles criollos en cosa alguna, .. . Y si na habido incendios de casas, muertes de familias y algunos desórdenes de los naturales, aparece haber sucedido esto en algunas partes, por haber experimentado ellos los mismos perjuicios por parte de los españoles, tanto en las personas mugeres e hijos, cuanto en todo género de bienes, que los exterminaron unidos con los corregidores aduaneros y chapetones y otras personas. . ."38. Continúa diciendo, que los corregidores se componen en el asunto de recaudar los tributos, de hacendados, puesto que "son muchísimos los yanaconas de haciendas, como sucede en la provincia de Paucartambo, y otras que muy raras son las comunidades, por ser todas de españoles, a las que se van huidos los naturales de los aillos, por librarse de tan legitima contribución de tributos". Los corregidores arruinan a todos los habitantes de la provincia con el reparto, tanto a españoles, como a naturales. A aquellos que no han pagado el reparto "despachan como vendidos o alquilados. . al trabajo de obrages y haciendas distantes, de cocales y cañaverales y sus bienes rescatan" 39 .

En el texto citado, "indios" o "naturales" designan a los campesinos, que huyen de los excesos y cargas, convirtiéndose en "yanaconas" o "forasteros", asalariados. Como campesinos se oponen tanto a los chapetones, como a los caciques, hacendados, mineros, yanaconas, etc.

Sólo si existe un discurso acerca de los indios-campesinos, se pueden observar algunos indicadores de clase, puesto que en los casos restantes hay tan sólo una enumeración de los diversos grupos de gente: Funcionarios del aparato estatal, propietarios de haciendas, minas, manufacturas, caciques. El autor del texto relaciona a estos individuos entre sí en razón de la explotación y de su participación en abusos, pero tal vez no los considera como miembros de un mismo grupo, pese a que en otro sitio haya escrito: "¿A todo el mundo es constante ser estos miserables indios más que esclavos, trabajando toda la vida para el logro de cuatro pícaros, que vienen a formar caudales con la sangre de los pobres i) or ellos atrasados los reales haberes: por ellos desnudos sin tener con que alimentar sus familias: por ellos hoy perdidos, abrasadas 
sus casas sin tener de que sustentarse. Y ¿querrán volver a chupar el último jugo que les queda, y a irrogar nuevos agravios?"40. No es ésto tan sólo una contraposición de pobres y ricos, sino la afirmación, de que tiene lugar una acumulación y contrapone el campesinado a aquellos que realizan dicha acuınulación, pícaros. Al fin, los capitalistas nuevos ricos obtuvieron un calificativo apropiado.

En el tratado celebrado con Miguel Thupa Amaro se afirma, que los naturales regresan a "labrar sus chacras", y para evitar "que los soldados salgan a campear y hacer perjuicios a los naturales y hacendados", los incas los surtirán en víveres y ganados ${ }^{41}$. A continuación, el tratado establece, que los incas permitan que los naturales abastezcan a la ciudad de La Paz "según y en la forma que desde la antigüedad lo hacían: Esto es por la correspondiente paga, y dejarán libres todos los caminos estrechos y parages, para que libremente transiten los españoles, mestizos, mulatos e indios, que fuesen comerciantes expresos" 42 .

La contraposición entre naturales-campesinos (llamados por Diego C. Thupa Amaro - indios) y hacendados-propietarios de haciendas, merece aquí unas palabras. Si los campesinos podían ser llamados naturales o indios, es de esperar, que los hacendados fueran llamados españoles, criollos o nobles. Resulta característico, el que en el texto de D.C. Thupa Amaro haya también una diferencia entre cacique e indio, la cual ya he tratado como diferencia estamental y no de clase, y esto que con algunas reservas.

En las declaraciones de Nicolás Catari, se ha registrado, que al minero Alvares "sus mismos coyarrunas le sacaron de la Gallota, se le entregaron, y con el común de indios. . . le quitaron la vida"43.

El término "común de indios" designa a la comunidad rural. La palabra "coyarrunas" es el plural de "coyarruna", y en contra de lo que parece, no es un etnónimo, sino la transcripción del quechua quya runa (q'uya runa, qhuya runa), hombre de la mina, minero, en el sentido de hombre empleado en la mina ${ }^{44}$.

En las declaraciones de Julian Apasa, es decir de Thupa Catari, el escribiente lo llama indio, y él mismo aclara, que es "natural del pueblo de Sicasica, criado y tributario en el ayllo de Sullcabi, 
del padrón inferior de forasteros, que su oficio es de viajero de coca, y vayetas" ${ }^{45}$. Aparece aquí la profesión, que explica que no es originario, es decir miembro de la comunidad con un derecho heredado a la tierra, sino un advenedizo o descendiente de ellos, ya establecido, puesto que está inscrito en la lista de tributarios. La palabra "criado" probablemente significa, que se alquilaba para diversas labores, o bien, es una repetición de la información contenida en la formulación del padrón inferior de forasteros, lo que es más probable, ya que al mismo tiempo es él del ayllo de Sullcabi ${ }^{46}$. A continuación, declara acerca de lo que pasó con las haciendas de los españoles, y que se rebelaron los indios de cierto arriero ${ }^{47}$.

Por lo general, en sus declaraciones aparecen tan sólo las haciendas de los españoles, parece ser entonces, que "españoles" significa aquí "dueños", "propietarios de haciendas", lo que puede confirmar el que se le emplee al lado del opuesto "indio-arriero". Este último evidentemente era un empresario de transportes, arriero de indios y no de mulas.

El 28 de enero de 1781, Julián Escalante escribe desde Acos a Píicaela Bastidas: "Los indios septanas y los de casa piden de comer, y a Dios para empezar a barbechar, me dicen que les de maíz o trigo, y dicen que hay en el troje. . . Y también dicen los indios que están desnudos. . ."48. Aquí "indios" significa campesinos, tanto los del común como los peones.

De los documentos hasta ahora citados parece resultar, que si los insurrectos, conspiradores o en general, contrarios al gobierno peruano de aquel entonces, se daban cuenta de la existencia de una división en clases, para su descripción se valían de los conceptos de la jerarquía de castas, de la de estamentos, de los nombres de las profesiones, y a veces del concepto de propiedad. Las autoridades y en general, los partidarios del virreinato, podían ver ésto de otra manera. Comprobémoslo.

En un memorial de la ciudad del Cusco del año 1768, he encontrado las siguientes expresiones: Mercader acaudalado, mitayos, mineros y caciques ${ }^{49}$. ${ }^{50}$. Al discutir los efectos de la actividad comercial de los corregidores se afirma, que el tesoro estatal recibiría mucho más por concepto del pago que harian los detallistas y pequeños comerciantes, que lo que ahora recibe si se suprimiesen 
las limitaciones ${ }^{51}$. Inmediatamente después, se mencionan dos grupos: "Indios yanaconas y yanaconas, que son los que se han reducido a servir en las haciendas de los españoles" 52 . Son ellos entonces: campesinos, peones, empresarios, mineros, grandes y pequeños comerciantes, corregidores y propietarios de haciendas, es decir españoles.

El corregidor de Arequipa distinguía pobres y ricos, pero también indios, de los cuales unos venden las cosechas y otros productos artesanales; y si son propios, al parecer del corregidor deberían estar exentos de pagar el arancel. En efecto, se ve una diferencia entre aquellos indios que son agricultores y artesanos y aquellos que son comerciantes ${ }^{53}$.

La relación acerca de los acontecimientos de Arequipa hace la distinción entre chacareros, arrieros, indios de pampa, vecindario noble y claro está, el corregidor y sus funcionarios ${ }^{54}$. Si "vencindario noble" designa en esta relación a los ricos ciudadanos de noble y claro está, el corregidor y sus funcionarios ${ }^{54}$. Si "vecindario noble" designa en esta relación a los ricos ciudadanos de Arequipa, no resulta claro en qué se diferenciaban los chacareros

También en Arequipa, I Iateo Urvicaín afirma, que en un comienzo los pasquines amenazaban con la expulsión de la ciudad a todos los europeos y forasteros tiranos, después agrega: "Estos pasquines iban poniendo a la nobleza en la mayor consternación, al paso que la plebe y gente del campo manifestaban en sus semblantes una gran complacencia, como que en ellos consistía el no ser tributarios de los aduaneros y verse libres de las opresiones a que los reducían los proyectos del administrador, y los que premeditaban sobre el jornal de los pobres, artesanos, panaderías, pulperías, puestas y ventanas" 55 . Aquí, el jornal es el ingreso diario y no el salario diario. Luego, describe la división social determinando las labores, o bien, el estamento y la casta.

El autor de la "Relación de los horribles estragos. .." de Oruro, escribe: "Procuró el corregidor con los demás vecinos de honor poner en defensa respetable sus personas y caudales: alistar soldados asalariados, y para ésto se 'echó mano de los cholos patricios que más son zambos e indios" 56 . Estos mismos soldados más adelante, serán llamados "criollos", o bien, "vecinos de 
honor-chapetones". Después, los "cholos rebeldes" (soldados rebelados), se unen con los indios de las rancherías, para juntos robar y matar a la gente a veces llamada "cnapetones", "españoles" o "gente blanca" 57 . Entre los rebeldes había también "indios forasteros" 58 . Una parte de ellos se repartió el contenido de las "caxas reales", afirmando que este dinero era de su "sudor y trabajo" 59 . Ahora resulta que las clases: Campesinos, peones, "burgueses" y propietarios de capitales, son designados con términos empleados para designar las castas y estamentos.

El autor de una carta de Cochabamba se queja, que "lian estos carniceros acabado con todos los que tienen la cara blanca", y agrega: "Si a los Yndios los hubieran mantenido en el Yanaconazgo sugetos como esclavos, sin permitírseles tanta libertad en las tierras de Comunidades, y Comercios con otras muchas excepciones que les ha permitido Nuestro Piadoso Irionarca, no se viera dano que sufre" 60 . En realidad, los yanaconas, por lo general endeudados y carentes de tierra propia, dependían del poder del hacendado mucho más, que los miembros de la comunidad, que sometidos al poder y a la jurisdicción real, tenían garantizada la propiedad de la tierra y otras libertades. Contrariamente a las apariencias, no es ésto un llamado a cambiar el status del estamento campesino, sino la proposición de expropiar la tierra a los campesinos. Demuestra ésto, que se percibían ya no dos estamentos, sino dos clases sociales: Campesinos y terratenientes, que desean disponer de la tierra y de la fuerza de trabajo.

Tales percepciones eran probablemente mutuas, de otra manera el fiscal de la Real Aidiencia de La Plata no afirmaría, que "rara será la hacienda que no fuese saqueada"

Cuando los oficiales vecinos y habitantes de Tupiza pidieron al Comandante General D. José Reseguín, que el ejército permaneciera en Tupiza, temian que el "enemigo situado en los pueblos ninerales. . ., después de haber dado muerte a los jueces y principales vecinos de los dichos pueblos" entrase a fuego y sangre en esta villa ${ }^{62}$.

Otro funcionario real escribe desde Jujuy el 1 de abril de 1781 , diciendo que el "linaldito nombre" "de su Rey Inca" "ila hecino perder el sentido a estos indios. pues muchos de mediana como- 
didad, y que lo pasaban muy bien, se han hecho a la parte de los Tobas"63. En los alrededores de Jujuy, se declaró a favor de la insurrección la tribu de los Tobas. El destinatario de esta carta escribe más tarde al virrey de Buenos Aires, que en Jujuy "la mayor parte de la gente común estaba rebelada"64.

La relación de Puno acerca de los acontecimientos de Juli y Chucuito afirma el 8 de abril de 1781, que en Juli, los insurrectos "no dexaron a uno de bien, tanto español como yndio"65. La comunidad de Indios de Mojo explicó al corregidor Joaquín de Orellana, que "ellos eran fieles al Rey, y que los rebeldes sólo eran los yanaconas de las estancias de españoles a quienes habian muerto y aniquilado después de sus ganados"66. Se ve aquí la contraposición entre "españoles dueños de las estancias" y sus "yanaconas", y también los indios comunes que constituyen la comunidad.

Celedonio Bermejo, autor de la relación sobre los acontecimientos 'ocurridos en la colindante con Puno, (Paucarcolla), provincia de Chucuito, sostiene, que en Yunguío, Desaguadero, Zepita y Pomata no se salvó ni un cacique, ni un español ${ }^{67}$.

Juan Bautista Zavala, un rico habitante de La Paz, pensaba, que "el indio será bueno con el continuo castigo no permiténcioles que estén ociosos ni menos que tengan plata que ésto ésta les sirve para sus borracheras y causar rebeliones. En adelante deben pagar tributo doble al Rey. Este debe quitar las comunidades, vender estas tierras a los españoles, sujetar a los indios a Santo Oficio de la Inquisición porque en el día tienen más malicia que nosotros, y quemar la Leyes de Indias. . ."68. Ya hemos encontrado este programa. Se puede leer como una tendencia hacia la transformación de las castas, estamentos y puede ser, que también de los grupos étnicos en clases sociales. El quemar las Leyes de Indias, el fin de las comunidades, la venta de tierras a los "españoles" y el aumento del tributo, cambiándole el nombre por el de "contribución de los indígenas", fueron introducidos finalmente con la victoria de los patriotas sobre los fieles al rey en Ayacucho. 
J. A. de Areche, el visitador, en su carta a Don José de Gálvez del 12 de mayo de 1780, escribe que: "Los que tienen conveniencias, comercios y frutos. . . son los que aquí llaman estado de la nobleza". Anteriormente había afirmado, al describir los acontecimientos de Arequipa, que: "la plebe no fue sino instrumento vil de los que se llaman nobles y hacendados"69.

Se podrían seguir dando ejemplos, sin embargo, todos muestran, que para describir la división en clases existente se valieron de la terminología de castas y estamentos, puede ser que también de una terminología "étnica". Basta preguntar, si las divisiones en clases eran percibidas como diferencias generales de la sociedad, o por el contrario, como subdivisiones de otras divisiones. Por último, no está claro, si fuera de las divisiones entre más y menos ricos y más y menos pobres, percibían la existencia de alguna clase como totalidad. El caso de los "indios", parece atestiguar a favor de la existencia de tal percepción, ya que aun en la Europa del siglo XX, la diferencia entre el campesinado como estamento y el campesinado como clase social es completamente obscura. Para finalizar, en los ejemplos dados, se puede apreciar claramente una tendencia a identificar las clases altas con los españoles, y las clases bajas con los indios, no viéndose por completo el lugar de otros grupos en tales identificaciones. Lntre los ejemplos, aparece dos veces la tesis, seguramente de los españoles, de convertir a los indios en yanaconas. Sin embargo, en todo caso resulta, que no se trata de asuntos estamentales, sino simplemente de asuntos de clase.

Como conclusión a las reflexiones hechas hasta el momento resulta, que los términos de la jerarquía de castas servían tanto para expresar un contenido estamental como de clase, ya gracias a diversas determinaciones, ya sin ellas.

\section{DE LA JERARQUIA CULTURAL}

La existencia en el Perú de 1780, de gente de diferentes culturas ha sido y es evidente, también, por ésto, no he escogido muchos ejemplos que muestren cómo eran percibidas tales diferencias culturales. 
Los autores de la "Representación de la ciudad del Cusco" emplean las siguientes expresiones: "Pobres y miserables como son los indios y gente de provincia"; "mestizos y gente de poca civilización"

Los clérigos obligan a los indios a realizar ceremonias llamadas: Occohaya, frescohaya, chaquihaya y cachaparri, "y aun se tienden a decir por sus antepasados que no fueron cristianos, y les obligan a sacar sus huesos de sus antiguas sepulturas para que les hagan las honras"71.

Esta práctica indica no tanto una diferencia de rituales, advertida tanto por los clérigos como por los autores del texto, sino también, un conocimiento de los antiguos y no cristianos cementerios. Los autores reprochan a los curas, que no enseñen a los indios el castellano, "por cuya falta hay pueblos donde no se oye ni nombra, y es cosa notable, que después de dos siglos y medio de conquista de un reino, no se haya introducido enteramente el propio lenguaje de los dominantes, cuando suele ser la primera idea y diligencia para que los naturales se hagan a su estilo y olviden sus antecedentes costumbres. .."72. Aquí, la diferencia de culturas y costumbres señala algo más: La división entre conquistadores y conquistados, que al mismo tiempo es la división entre los dos grupos étnicos.

Bernardo Tambohuacso, cacique por nosotros ya conocido, indio noble, el 10 de agosto de 1780 , durante una sesión del tribunal, fue llamado "indio ladino"73. El término "ladino" se repite varias veces en las fuentes y designa a aquel individuo que se expresa fluentemente en español, aunque no sea ésta su lengua materna. Este término, por lo común aparece acompañado por el de "indio", lo que parece sugerir, que los españoles del lugar, los mestizos, etc., de por sí deberían conocer el español, lo que no los distingue de los otros miembros de su casta o estamento. Con el término "indio" es menester, sin embargo, señalar si es "ladino", de la misma manera como en otros casos se indica si es "noble", "cacique", "principal".

Un testigo de la ejecución de J. G. Tilupa Amaro y de sus compañeros el 18 de mayo en el Cusco, probablemente un chapetón o un criollo, escribe: "En este día concurrió un crecido número de 
gente, pero nadie gritó ni levantó una voz: muchos hicieron reparo, y yo entre ellos, de que entre tanto concurso no se veían indios, a lo menos en el trage mismo que ellos usan y si hubo algunos, estarian disfrazados con capas o ponchos. Suceden algunas cosas que parecen que el diablo las trama y dispone, para confirinar a estos indios en sus abusos, agüeros y supersticiones. . ."74 El autor del texto percibe las diferencias existentes en el vestir, la religión y en general, entre la concepción indigena del mundo y la propia.

il reconocerse mutuamente por el vestir, o en general, por la a:ariencia exterior ataĩe también a los indigenas. El autor de la relación de lo acontecido después de la batalla de Sangarara afirma, que: "Dieron muerte a cuantos españoles hallaron de ambos sexus repuntando por españoles o mestizos a todos los que tenian camisa"75. Se refiere aqui, a las camisas de un corte usado por los no-indigenas, el tipo de camisa se convierte aquí, en un elemento de identificación de los grupos de españoles, compuestos de espairoles y mestizos, o tal vez también de individuos pertenecientes a otro grupo étnico.

iste mismo criterio de identificación es dado por R.J. Sahuaraura Tito Atauchi" quien dice: "A los Incas y caciques nobles, con más otros descendientes de la real sangre de los liıcas, en ambos virreynatos, cuasi integramente los consumieron, por decir que siendo hijos de su ivación, se hagan partidarios de los españoles, como si los nobles fueran indios de su especie infima"77. R.J. Sahuaraura utiliza aquí conceptos de diversas divisiones, pero en comparación con la cita inmediatamente anterior se ve, que en la división en "indios" y "españoles" se tenían en cuenta criterios culturales, y no tan sólo los otros, y que al parecer de R.J. Sahuaraura, independientemente al origen, el español es superior al indio, y que el Inca es también español. Eatonces, el individuo que usa camisas de corte español es superior a aquel que no usa tales camisas, puesto que es más noble.

Antonio Cionzález Pavón distingue entre los indios rebeldes a aquellos, que son más o menos ladinos, pero para él es evidente, que los indios tienen su lengua ${ }^{78}$ y su religión ${ }^{79}$. 
Ignacio de Castro sostiene, que todos los naturales hablan en quechua así, que aun las damas del lugar, aunque con los españoles hablen en español, con el resto lo hacen en quechua. $Y$ a continuación agrega, que: "De aquí viene que sea preciso, que predique y enseñe la Doctrina Cinristiana en la lengua índica; pues a más de que ésta en los indios es casi la única, también la entienden todos los españoles; y aunque éstos suelen tener a poco honor asistir a estos sermones en aquel idioma, porque los convencería de que no entienden bien el español, con todo si alguna vez van, creeré que exceptuando a los de más noble educación, salgan más aprovechados, que cuando se les anuncia la palabra de Dios sólo en castellano"80. Este parecer confirma no sólo la coexistencia de lenguas, sino también su apreciación. PJos enteramos ahora, que los españoles (sean quienes fueran) tienen por superior el castellano al quechua, aunque conozcan mejor el segundo.

En la localidad de Tiquina, un enviado de Thupa Catari comunicó el 19 de marzo de 1781, según la relación de Fray lisatías de la Borda, que: "Manda el Soberano Inga que pasen a cuchillo a todos los corregidores, sus ministros, caciques, cobradores y demás dependientes: como así mismo a todos los chapetones, criollos, mugeres e niños de ambos sexos, y toda persona que sea o parezca ser española, o que a lo menos esté vestida a imitación de tales españoles. . . que así mismo no tuviesen los yndios sus consultas en otros lugares que no fuesen en cerros, procurando no comer pan, ni beber agua de las pilas o estanques sino enteramente separarse de todas las costumbres de los españoles" $"$.

Tenemos esta vez un ejemplo dè valoración indígena, quienes al distinguir las culturas, tuvieron la propia como la única, como la que debería existir. Este mismo monje describe la disposición de Thupa Catari, prohibiendo el uso de la lengua española y ordenando la obligación de hablar solamente en aymara ${ }^{82}$.

En Oruro los insurrectos mandaron a todos llevar "trage indiano" $"$.

La lista de ejemplos puede prolongarse sin cesar, resultando siempre lo mismo: La apreciación de las dos culturas, o como entonces se les llamaba, de las dos costumbres, y el grado de hispanización: Español, ladino, indio. 
En las fronteras del Perú de entonces, o más exactamente, en Jujuy, situado a los bordes de los terrenos abarcados por la insurrección, las distinciones parecían ser un poco distintas. A causa de la directa vecindad de tribus independientes o recién conquistadas, se hacía la distinción entre cristianos y no-cristianos, y finalmente entre los cristianos en criollos y otros ${ }^{84}$.

Las consideraciones hechas hasta el momento muestran, que se percibian las diferencias culturales, que se las calificaba y se las trataba también, según otros criterios de casta, estamento, clase y grupo étnico, como parte de la diferenciación de la sociedad. Puesto que la calificación de las diferencias culturales se repite al analizar cada una de las jerarquías consideradas, me ocuparé de ello por aparte.

\section{DE LAS DIVISIONES ETNICAS Y DE CIVILIZACION}

La percepción de las divisiones étnicas, o de civilización se puede observar de dos maneras: O bien comprobando si existen términos generales que designen tal tipo de divisiones, o también, a través de la investigación de las autodenominaciones y de la comparación de estos términos con los nombres de los vecinos. Hasta el momento, al analizar las jerarquías resulta, que existe un nombre general (castas, estamentos, clases), pero que es utilizado raramente; en el caso de las divisiones culturales se habla tan sólo del grado de civilización o de barbarie.

En el Tawantinsuyu independiente se denominaba a los bárbaros con los siguientes términos: Awqa - enemigo, o c'uncu salvaje. Estos nombres se referían a los habitantes de la selva (c'uncu) y a aquellos de las montañas (awqa) si se encontraban fuera de los lírnites del Tawantinsuyu, del mundo civilizado. He escogido entonces, aquellos fragmentos de las fuentes, en los cuales se habla de los chunchos (c'uncu), o de los paganos (gentiles), o infieles.

Según la "Representación de la ciudad del Cusco" los deudores de los corregidores "desamparan sus casas y lo que es más doloro- 
so, la religión entrándose a la habitación de los infieles"85 ; los autores se lamentan también, porque los indios huyen a las montañas "apostando la religión, disminuyendo los reales tributos" J.A. de Areche al contestar a la solucitud de J.G Thupa Amaro de 1777 , sostiene que "la noticia de lo que padecen los indios, contra las intenciones del Gobierno y de la Ley, transmigra hasta lo más escondido de los aduares, o ranchos de los gentiles" ${ }^{87 .}$. El corregidor de la provincia de Pasco informó a Lima el 22 de marzo de 1780, que en la frontera con los indios gentiles hay tranquilidad, las únicas expresiones que emplea son: "Indios gentiles" y "gentiles" 88 .

Manuel Pablo Guaman Sullca, en carta a J.G. Thupa Amaro Inga, presumiendo de las armas y hombres que pone a disposición del Inga, subraya que son diestros en el guerrear con los infieles chunchos $^{89}$. J.G. Thupa Amaro, en carta al canónico J. Paredes, dice que los corregidores reparten "aniquilando de plano a los miserables criollos" así, que "el miedo los hace huir a los chunchos" 90 . En esta carta aparece la palabra "criollo" con un sentido particular: criollo es cada subordinado a la autoridad del corregidor, especialmente el indígena.

En otra carta, el Inca escribe, que a los desgraciados provincianos, españoles e indios, a veces le queda sólo entregarse a otras naciones infieles ${ }^{91}$.

El autor de la carta fechada en el Cusco el 20 de marzo de 1781, temía que J. G. Thupa Amaro huyese por los montes "a la montaña de los chunchos"92.

El llamamiento hecho en Azángaro por D. C. Thupa Amaro el 29 de agosto de 1781 , reprocha a los corregidores, el que no hubiesen conquistado a los chunchos, y que el reino se componga sólo de aquello que habían ya conquistado "mis antepasados Reyes Ingas nobles" $"$.

Nuevamente podemos decir, que abundan los ejemplos, Chunchos e indios infieles, gentiles, son siempre lo mismo: Tribus libres, no conquistadas, que habitan ya fuera del alcance del dominio español. He encontrado también, algunos ejemplos de tribus fronterizas, parcialmente conquistadas; por lo común en los do- 
cumentos aparecen también las expresiones "cristianos", "paganos" y los nombres tribales: Tobas, Lecos y otros"

De lo anterior resulta, que el significado de la palabra "chuncho" (c'uncu) no ha cambiado mucho, desde los tiempos de la conquista. Aún significa salvaje, infiel, habitante de la selva, fuera del alcance de la autoridad y la civilización. Se suele tratarlo como un ser inferior, pero también, hacia él se puede huir.

Las fuentes de las que dispuse, no muestran tangiblemente la forma en que se trataba la pertenencia a una patria chica determinada. Ciertamente, en los textos aparecen arequipeños, cochabambinos o cusqueños y limeños, y también gentilicios de otros centros menores: Pocoatas de Pocoata, o machas de Macha, pero no hallé prueba alguna que indicase que estas distinciones estuviesen hechas sobre una base étnica. Puesto que el problema de las divisiones étnicas entre los habitantes del Perú (divisiones entre chapetones, criollos e indios) será discutido más adelante ${ }^{95}$, sólo nos quedan por considerar aquellos conceptos que se pueden referir a la totalidad de los habitantes del Perú o de las Indias.

Uno de estos términos es "indiano". Lo he encontrado sólo en tres oportunidades. En el primer caso aclara, que el corregidor de Puno no era chapetón, sino indiano ${ }^{96}$. El ya conocido R. J. Sahuaraura Tito Atauchi escribe, que los insurrectos "decían que buscaban a los corregidores y puca cuncas, y mataban a tantos criollos, indianos, españoles, sin reserva de sexo"97. Aquí, indiano es un habitante de las Indias, pero no originario del Perú, probablemente un blanco.

Al fin, según A. González Pavón, cada habitante de las Indias es un indiano, entre ellos hay igualmente indios ${ }^{98}$. Encontré aun dos menciones acerca de los "indianos", pero ninguna de ellas se refiere a los indígenas, ambas son el producto de la pluma de fieles a España.

La palabra "peruano" aparece raramente. En un pasquín de Arequipa, "peruano" designa a los habitantes del Perú (en este caso de Arequipa), llamados también "patrianos" (de patria) y opuestos a foráneos o forasteros (extranjeros). En este mismo texto, se encuentra la siguiente frase: "Casimiro el Inca, viva! a quien juramos por Rey, que es de razón y de ley, que lo que es 
suyo aperciba. Morir por su Rey" 99 . Si en el concepto de "peruano" cabe cualquier Inca, con lo cual se subraya que es indio ${ }^{100}$, entonces, también los indígenas caben en el concepto.

J. G. Thupa Amaro inicia su famoso "Bando de la libertad de los esclavos" con las palabras: "Hago saber por éste a los peruanos vecinos estantes y havitantes de la ciudad del Cusco paysanaje de españoles y mestizos, religiosos de todas las que contiene dicha ciudad, clérigos y demás personas distinguidas que hayan contraído amistad con la Gente Peruana concurren en la distinguida empresa que hago favorable al bien común de este Reyno por constarme las hostilidades y vejámenes que se experimenta de toda Gente Europea. . ."101. En el significado dado a esta palabra por el Inca, peruanos son todos aquellos habitantes del Perú, exceptuando a los europeos. En un significado similar emplea este término R. J. Sahuaraura Tito Atauchi ${ }^{102}$.

Los ejemplos restante de la palabra "peruano", o presentan el mismo significado, o no se refieren a la gente, sino al territorio, señalando los límites del Perú o hablando sobre el Imperio Peruano. Sin embargo, ya que las fuentes de las que dispuse, excepción hecha del análisis del programa de la insurrección, no suministran información alguna acerca de lo que se consideraba como parte del Perú, podemos renunciar a estos casos, pues no aportan nada nuevo a la comprensión del término. En todo caso, "peruano" es al entender de los autores de las fuentes aquel que escribe en español, independientemente del habla, lengua y apariencia del individuo nacido en el Perú.

Puede ser, que a causa de la tradición lingüística polaca, en la cual la palabra nación tiene una fuertísima relación con las divisiones étnicas, pero también, porque era el único término (además de los etnónimos, del tipo: Español, indio, etc.), que se refiere en general a las divisiones étnicas, que escogí aquellos fragmentos en los cuales aparecía la palabra "nación". Se encuentra ella en cuatro documentos, el autor de dos de ellos es J. G. Thupa Amaro.

El Inca escribe en una carta al Obispo del Cusco, que su ojetivo es conseguir la "libertad absoluta en todo género de pensiones" para su nación ${ }^{103}$. Tres meses más tarde escribe a J.A. de Areche 
acerca del "entregarse a otras naciones infieles, como lo han hecho muchos indios"104.

Cierto realista prisionero del Inca, probablemente un chapetón, e indudablemente coronel de la milicia en la provincia de Azángaro, se libró de ser ahorcado, diciendo al Inca y a los insurrectos, que es limeño de nación ${ }^{105}$.

Todo este asunto parece indicar, que en verdad, el limeño era tenido por alguien completamente distinto a un Qusqu runa, no llegando a ser un chapetón, puesto que el reconocerlo como limeño le salvó la vida.

La palabra "nación" también es empleada por J.A. de Areche en la sentencia dada contra el Inca. Primero habló de una "nación mal educada", a la que el Inca pertenece, después sobre una "ilusa nación de indios"106.

J. A. de Areche era desde el punto de vista de los habitantes del Perú que conocían el español, un chapetón, pero un puka kunka desde el punto de vista de aquellos que hablaban en quechua. El mismo, pese a que vivía ya varios años en el Perú, no veía la contraposición descrita en el citado "Bando de la libertad de los esclavos", entre peruanos y europeos (chapetones) ${ }^{107}$, sino entre españoles (no importando de quien se trate), e indios.

Independientemente de su carácter, si el funcionario más poderoso de aquel entonces en todo el virreinato del Perú y en el de La Plata, consideraba tal contradicción como la más importante, es menester que la veamos más de cerca. Con tal objeto, he escogido dos problemas: El concepto de conquista, y la contraposición indios-españoles, no teniendo en cuenta esta.vez, el asunto de los chapetones.

La actitud ante la conquista, será discutida en detalle en otro sitio $^{108}$ aquí, ésto nos es necesario, tan sólo en cuanto la comprensión de la conquista ha influido en la significación de los conceptos que caracterizan las divisiones étnicas.

El mismo J. A. de Areche sostiene, que los indios tienen el "día y tiempo de la conquista por fatal, y nosotros por feliz, pues se unieron al gremio de la Iglesia Católica y a la amabilísima y dulcísima dominación de nuestros Reyes"109. 
$\mathrm{Su}$ oponente, J. G. Tnupa Amaro, escribe en su proclamación real fechada en Tungasuca el 26 de noviembre de 1780, que: "Los Reyes de Castilla me han tenido usurpada la Corona y dominio de mis gentes cerca de tres siglos"110.

Según una relación de comienzos de la insurrección, al iniciar la ceremonia de ahorcamiento de un corregidor, el Inca, vestido con sus insignias regias declaró en quechua ante la multitud reunida, que: "Era llegado ya el tiempo en que debían sacudir el pesado yugo que por tantos años sufrían de los españoles"111.

He citado ya anteriormente la "Representación de la ciudad del Cusco", cuyos autores se extrañan que después de dos siglos y medio de dominación, los dominados no hayan aprendido la lengua de los dominantes ${ }^{12}$. Ignacio de Castro continúa la comparación entre el imperio mejicano y el peruano, evidentemente a favor de este último, con lo que la conquista del Perú supera a la de ¿ ́éjico y Pizarro a Cortez ${ }^{113}$.

A propósito de la conquista aparece también la palabra reconquista. Los cuatro americanos, que comandaban el ejército que combatía a los insurrectos, son llamados reconquistadores en un verso anónimo de abril o mayo de $1781^{114}$. El acto de sofocar la insurrección, es llamado también reconquista por R. J. Sahuaraura Tito Atauchi ${ }^{115}$.

Estos ejemplos de la actitud ante la conquista indican la perduración de una división extraordinariamente importante, en conquistados y conquistadores; dominados y dominantes. Así, como la existencia de ciertas identificaciones: El dominante es español y habla en castellano; el conquistado es indio, también Inca y habla en quechua. Tal contraste de términos entre indio y español no cabe en ninguna de las jerarquías y divisiones hasta el momento consideradas. Constituye él otro orden, que hasta el momento no hemos tenido en cuenta.

Para conocer la importancia y la calidad del contraste entre indios y españoles, he seleccionado ochenta y siete citas de las fuentes, en las cuales aparecen los términos: Indio, español, mestizo, cholo, criollo y eventualmente algún otro, de cualquiera de las jerarquías hasta ahora consideradas, a condición de que tengan un significado étnico. No he tenido en cuenta aquí, los otros signifi- 
cados que pudieron haber tenido estos términos. Luego, anoté las contraposiciones de estos términos, separando aquellos casos especiales en los que dos términos o más se contraponen a otros. $\mathrm{El}$ efecto de esta labor es la Tabla 4. Esta tabla confirma los resultados de las consideraciones acerca del concepto de "conquista". La división más frecuente, es aquella entre indio y español (no importa lo que estos términos designen). Y si aún consideramos el término "cholos", como término que designa cierto subgrupo, aumenta la importancia de la división en indios y españoles sobre las restantes. Resulta característico el que se contraponga más frecuentemente a los mestizos con los españoles que con los indios. En la contraposición entre españoles y americanos, se encuentran de un lado los chapetones y del otro a veces los peruanos, pero más a menudo diversos grupos peruanos. Parece que esta contraposición se presenta más en las declaraciones programáticas de los insurrectos que en cualquier otro sitio; esta cuestión la discuto ampliamente en mi libro "Los objetivos de los tupamaristas. . . etc.". Sea como fuere, la debilidad numérica de este último caso (13 casos sobre 114) indica, que incluso si la contraposición chapetones-habitantes del Perú era conocida y percibida, era mucho más importante en la vida cotidiana aquella entre indios y españoles, contraposición en la cual los cholos se hallaban en el extremo "indios" y los mestizos en el de "españoles". Las castas negras (negros, zambos, mulatos, etc.) carecen aquí de importancia, debido a que en el sur del Perú y en el Alto Perú, los individuos de estos grupos eran poco numerosos.

Estas consideraciones pueden ser objetadas, debido a que se basan en fuentes bastante parcializadas, sobre todo realistas y por lo general fruto de la pluma de los blancos. Lo anterior es evidentemente cierto, pero son éstas, también, fuentes que describen un conflicto social, en base a conceptos ampliamente conocidos aún por los destinatarios de los textos, que a veces eran todos, a veces conocidos, y a veces los superiores. Se concluye entonces, que de todas las contradicciones étnicas, la más importante es aquella entre indio y español, descrita con términos también empleados en la descripción de las divisiones sociales. Indudablemente, existía también una contraposición peruano-español. Puede ser que sea menester hablar de los tres grandes grupos étnicos: Españoles, es decir, chapetones-españoles de España; españoles criollos, lla- 
mados también españoles americanos o peruanos, y a veces indianos; e indios llamados también a veces naturales o peruanos, a los cuales se puede llamar Tawantinsuyu runa -gente del Tawantinsuyu.

\section{CONCLUSIONES}

De las anteriores reflexiones, se puede concluir lo siguiente:

Los autores de las fuentes, al pensar̃ en españoles, o en todo caso, al escribir en español han utilizado conceptos que designan la pertenencia a un grupo étnico, civilización, cultura, estamento, castá, clase-estrato social, o profesión. Si exceptuamos el término que designa la profesión, que también designaba el lugar ocupado èn la estructura de clases de la sociedad, podremos decir, que utilizaron sobre todo los términos de la jerarquía de castas, empleados con no muy grandes modificaciones en la descripción de las divisiones restantes. En casos más complejos, utilizaron términos adicionales, que determinaban las obligaciones o privilegios: rinitayo, tributario, originario, forastero, noble, esclavo, etc.

Consideraban la sociedad como compuesta de dos civilizaciones, culturas o naciones: indios y españoles. Algunos, la consideraban como compuesta de tres grupos nacionales: Cinapetones, españoles criollos e indios. Al mismo tiempo, se dieron cuenta, que entre aquellos grupos existían relaciones de dependencia: Españoles arriba, indios abajo; o chapetones en la cúspide, españoles criollos en el medio e indios abajo.

Creían, que esta misma sociedad estaba compuesta de varias castas: Indios abajo, "gente de casta" en el medio, los negros también abajo, los mestizos mucho más arriba y en la misma cima los españoles, entre los cuales los chapetones eran la flor y nata.

Se puede describir esta misma sociedad, como compuesta por varios estamentos: Gente flotante-forasteros, que quedan fuera de la jerarquía; indios tributarios (campesinos de las comunidades); cholos, zambos y mestizos, que constituyen la "burguesía", en la cual los mestizos son los patricios y los cholos y zambos, la plebe, es decir, el estamento intermedio entre tributarios y nobles; nobles es decir, españoles, entre los cuales se incluía también al Inca, 
iust'a y quya, así, como a los caciques y principales. Un poco aparte, veían a los esclavos llamados también negros, y a los eclesiásticos, es decir, a los sacerdotes.

Por último, gracias a estos mismos términos se podía ver la sociedad dividida en clases o estratos sociales: Indios (campesinos), forasteros o también jornaleros, cholos y otras castas, hacendados, caciques, mineros, arrieros. Pero también: Españoles, funcionarios (ministros), corregidores e individuos con ellos relacionados.

Lo anterior, no significa que los autores de las fuentes siempre hayan empleado un determinado término e.g. "indio", en un único e inequívoco sentido. Para ellos era sencillamente indio, no preocupándose si se le empleaba como nación, cultura, casta o estamento. Probablemente, ésto se refiera también a los otros conceptos utilizados para designar los grupos sociales. Algunos de ellos, grupos grandes e importantes: Indios españoles; otros, en el Sur del Bajo Perú y en el Alto Perú, poco importantes: Esclavo, negro, mulato, pardo, etc.

Estas reflexiones nos dicen sólo un poco acerca de los conceptos empleados por los participantes en los acontecimientos, quienes escribian y hablaban en español, al clasificarse a sí mismos y a sus contrarios. Los conceptos usados por ellos eran comprensibles para sus contemporáneos, aunque no necesariamente para todos, ya que en el sur del Bajo Perú y en el Alto Perú sólo un grupo insignificante de individuos hablaba y pensaba en español. Para el historiador significa ésto, la necesidad de considerar los conceptos que pudieron haber sido empleados por aquellas personas que desconocian el español, es decir, por aquellos que quedaban bajo la gran influencia de la tradición y la civilización precolombinas.

Por último, el investigador no puede aceptar el significado de los términos de la jerarquía de castas como algo evidente, debe cada vez, o bien comparar el uso de cada uno de ellos con el de otros términos en los documentos relativos a la misma cuestión, o bien, si no está en capacidad de decidir en qué sentido era empleada una palabra determinada en un documento dado, al menos contar con la posibilidad de no haber entendido el documento. Desafortunadamente, tal costumbre parece no existir todavía entre los latinoamericanistas, puesto que cada uno ve cual es la situación existente. 


\section{TABLA 1}

\section{Términos que supuestamente Términos a los cuales Fuente pertenecen a la jerarquía se contraponen de castas}

mestizos, españoles, indios:

indios:

indios:

indios:

indios, mestizos:

español, indio:

español, indio:

indio:

español, indios:

indios, zambos, cholos:

indios, mestizos, cholos:

indio:

español, mestizo:

español mestizo, indio:

indios, cholos, mestizos:

españoles:

españoles, mestizos:

zambo, cholo, mestizo:

indio:

mestizo:

mestizos, negros, zambos, indios: indio, mestizo:

cholo, zambo, indio:

indio:

indios. mestizos:

españoles, mestizos:

español, mestizo:

españoles, mestizos:

mestizo:

gente blanca:

indios y otras castas:

mestizo:

indios:

indio:

criollos, indios:

negros, zambos, mulatos:

caciques
nobles
principales, tributarios
ministros
vecinos
cacique, ladino
principal
noble
noble, vecino, forasteros
naturales, tributarios
tributarios
noble, ladino, principal
gobernador, cacique
criollo, americano
vulgo
nobleza
vecinos
tributario
natural, forastero
noble
plebe
indio forastero
patricio
arriero
plebe
los que tienen camisa
criollo, principal
vecinos
indio
españoles
plebe
español
principales
cholo
principales
esclavos

CDIP 2, 1 p. 18

CDIP 2, 1 p. 18

CDIP 2, 1 p.

CDIP 2, 1 p. 34

CDIP 2, 1 p. 10

CDIP 2, 2 p. 38

CDIP 2, 2 p. 45

CDIP 2, 2 p. 46

CDIP 2, 2 p. 99

CDIP 2, 2 p. 147

CDIP 2, 2 p. 149

CDIP 2, 2 pp 183-19u

CDIP 2. 2 p. 242

CDIP 2, 2 p. 256

CDIP 2, 2 p. 278

CDIP 2, 2 p. 278

CDIP 2, 2 p. 486

CDIP 2, 2 p. 489

CDIP 2. 2 p. 489

CDIP 2, 2 p. 489

CDIP 2, 2 p. 495

CDIP 2, 2 p. 497

CDIP 2, 2 p. 503

CDIP 2, 2 p. 418

CDIP 2, 2 p. 418

CDIP 2, 2 p. 426

CDIP 2, 2 p. 585

CDIP 2, 2 p. 586

CDIP 2. 2 p. 608

CDIP 2. 2 p. 62

CDIP 2, 2 p. 766

CDIP 2, 2 p. 814

CDIP 2, 2 p. 813

FAL pp. $140-185$

JCB pp. $426-431$

JCB pp. $426-431$ 
españoles, mestizos, mulatos.

indios:

naturales:

mestizo:

indios:

cholos:

españoles:

indios:

españoles:

blancos:

indio:

indio:

indio:

espariol: comerciantes

ladinos

panadero

collana

indios

nobles

bajos

sacerdotes

indios

Inca. noble, cacique

noble, cacique

forastero

español
CDIP 2. 3 p. 145

CDIP 2, 3 p. 143

CDIP 2. 3 p. 171

CDIP 2. 3 p. 172

CDIP 2. 3 p. 172

CDIP 2. 3 p. 203

CDIP 2. 1 p. 359

CDIP 2. 1 p. 359

CDIP 2.1 p. 363

CDIP 2. 1 p. 365

CDIP 2.1 p. 102

CDIP 2. 1 p. 118

CDIP 2. 1 p. 195

\section{TABLA 2}

Términos que supuestamente Términos a los cuales pertenecen a la jerarquía estamental

Contraste con los términos de la jerarquía de castas

\begin{tabular}{|c|c|}
\hline $\begin{array}{l}\text { noble: } \\
\text { noble: } \\
\text { noble: }\end{array}$ & $\begin{array}{l}\text { español } \\
\text { mestizo } \\
\text { indio }\end{array}$ \\
\hline noble: & natural \\
\hline espanol: & blanco \\
\hline español: & español \\
\hline cspañol: & indio \\
\hline blanco: & indio \\
\hline Inca: & indio \\
\hline Inca: & español \\
\hline cacique: & español \\
\hline cacique: & mestizo \\
\hline cacique: & indio \\
\hline
\end{tabular}

Fuente (número)

3122733

320

$24 \cdot 71518242729$

$31 \cdot 34$

2736

2330

33

8

33

8252933

33

733

1135

5781117333440 41 


$\begin{array}{lll}\text { cacique: } & \text { natural } & 36 \\ \text { principal: } & \text { español } & 7 \\ \text { principal: } & \text { mestizo } & 22 \\ \text { principal: } & \text { indio } & 578102234 \\ \text { principal: } & \text { natural } & 110 \\ \text { patricio: } & \text { indio } & 28 \\ \text { tributario } & \text { indio } & 35914203839 \\ \text { mitayo, originario: } & \text { natural } & 20 \\ \text { tributario: } & \text { zambo } & 1420 \\ \text { tributario: } & \text { cholo } & 142038 \\ \text { tributario: } & \text { mestizo } & 152038 \\ \text { tributarios: } & \text { otras castas } & 38 \\ \text { tributario: } & \text { criollo } & 39 \\ \text { indio: } & \text { indio } & 41 \\ \text { indio: } & \text { natural } & 36 \\ \text { natural: } & \text { indio } & 1014 \\ \text { natural: } & \text { zambo } & 14 \\ \text { natural: } & \text { cholo } & 14 \\ \text { natural: } & \text { natural } & 10 \\ \text { esclavo: } & \text { negro } & 21 \\ \text { negro: } & \text { negro } & 9 \\ \text { mestizo: } & \text { indio } & 26\end{array}$

\section{Otros contrastes}

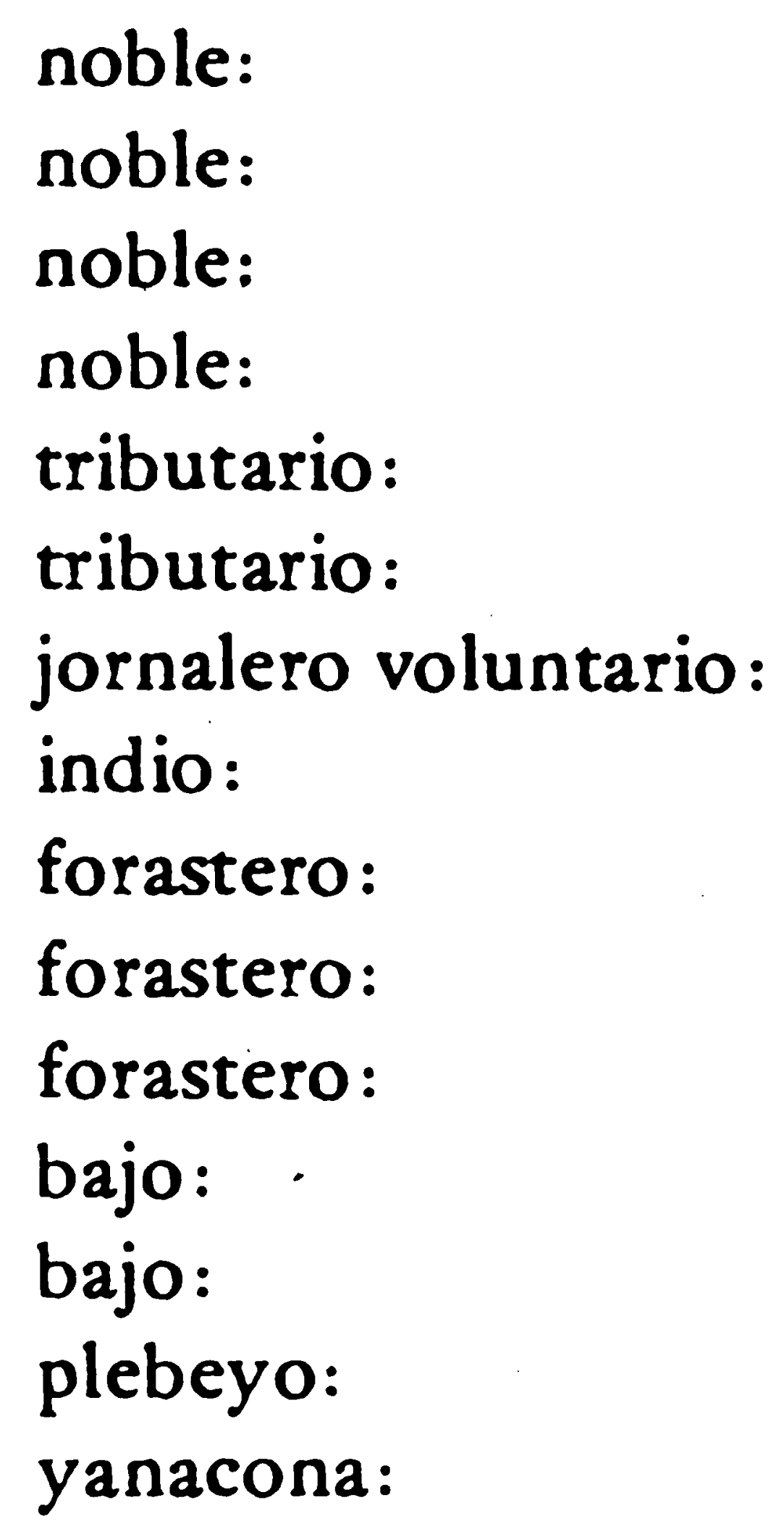

$\begin{array}{ll}\text { hacendado } & 16 \\ \text { comerciante } & 17 \\ \text { cacique } & 37 \\ \text { vecino } & 1319 \\ \text { forastero } & 20 \\ \text { yanacona } & 39 \\ \text { indio } & 9 \\ \text { forastero } & 19 \\ \text { indio } & 61421 \\ \text { zambo } & 14 \\ \text { cholo } & 14 \\ \text { indio } & 3233 \\ \text { español } & 33 \\ \text { indio, español, natural } & 27 \\ \text { indio } & 5\end{array}$




\section{Fuentes:}

\begin{tabular}{|c|c|c|c|}
\hline $1 /$ & CDIP 2.2 p. 17 & $21 /$ & CDIP 2.2 pp. 506 \\
\hline 21 & CDIP 2.1 pp. $74-76$ & $23 /$ & CDIP 2, 2 p. 489 \\
\hline $3 /$ & CDIP 2.1 p. 38 & $24 /$ & CDIP 2. 2 p. 770 \\
\hline 41 & C.DIP 2. 1 pp. $39-40$ & $25 /$ & CDIP 2. 2 p. 772 \\
\hline $5 /$ & CDIP 2.1 p. 33 & $26 /$ & CDIP 2, 2 pp. 818,819 \\
\hline $6 /$ & CDIP 2,1 p. 24 & $27 /$ & CDIP 2. 4 p. 244 \\
\hline $7 /$ & CDIP 2. 2 pp. $45 \cdot 46$ & $28 /$ & CDIP 2.1 p. 512 \\
\hline $8 /$ & CDIP 2. 2 p. 41 & $29 /$ & CDIP 2. 3 p. 267 \\
\hline $9 /$ & CDIP 2.2 pp. $84-86$ & $30 /$ & JCB pp. $458-459$ \\
\hline $10 /$ & CDIP 2.2 p.90 & $31 /$ & CDIP 2.3 p. 366 \\
\hline $11 /$ & C.I)IP 2.2 p. 93 & 321 & CDIP 2, 1 p. 387 \\
\hline 121 & CDIP 2.2 p. 99 & 331 & CDIP 2.1 pp. 363.366 \\
\hline $13 /$ & CDIP 2.2 p. 146 & 341 & CDIP 2.1 p. 162 \\
\hline $1+1$ & CDIP 2.2 p. 147 & 351 & CDIP 2.1 p. 99 \\
\hline $15 /$ & RAHC: No. 12.1967 p. 221 & $36 /$ & CDIP 2.1 p. 100 \\
\hline $16 /$ & (CI)IP 2.2 p. 176 & 371 & CDIP $2.1 \mathrm{p} .111$ \\
\hline $17 /$ & CDIP 2.2 p. 178 & 381 & CDIP 2, 1 p. 690 \\
\hline $18 /$ & CDIP 2.2 p. 183 & 391 & CDIP 2.1 p. 701 \\
\hline 191 & CDIP 2.2 p. 493 & $40 /$ & CDIP 2, 1 p. 429 \\
\hline $2(1) /$ & CDIP 2, 2 p. 489 & $41 /$ & CDIP 2.1 p. 426 \\
\hline
\end{tabular}

TABLA 3

\section{Estamento}

noble
Sinónimo

Español

blanco

chapetón

patricio

Inca

ñust'a
Número de las citas

$237-9182023-25$

28293132444548 .

$5053565760-6265$

6869

$1011363739-4249$

515458

56

33

47

14294555

13 
cacique

principal

mestizo

zambo

hombre de casta

indio

forastero

yanacona

jornalero voluntario

bajo, hombre de cuna baja

vulgo

plebeyo

pueblo

esclavo

eclesiástico, sacerdote tributario

natural

mitayo

indio originario

indio ordinario
26101117192930

$36394059-66465$

$69-71$

12101114161938

616465

31373946

31

32

$620242630-3437$

5460656670

$2-41522666772$

116213154

156667

15

13

721313463

267

15

3557

28

4548

49

1527344352

153334

3758

\section{Fuentes:}

$1 /$ CDIP 2. 2 p. 17

2) CDIP 2, 1 p. 33

3/ CDIP 2, 1 p. 28

4/ CDIP 2.1 p. 39.40

negro

5/ CDIP 2, 1 p. 42

6/ CDIP 2, 1 p. 21

7/ CDIP 2, 1 p. 24

8/ CDIP 2, 1 p. 74

9/ CDIP 2, 2 pp. $26-29$

10/ CDIP 2. 2 p. 41

11/ CDIP 2, 2 pp. 45, 46

13/ CDIP 22, 2 pp. 50, 51

14/ CDIP 2. 2 p. 54

15/ CDIP 2, 2 pp. 84 - 86

16/ CDIP 2, 2 p. 90 
$17 /$ CDIP 2, 2 p. 93

18/ CDIP 2, 2 p. 99

19/ CDIP 2, 2 p. 105

20/ CDIP 2, 2 p. 146

21/ CDIP 2, 2 p. 147

221 RAHC No. 12,1967 p. 221

23/ CDIP 2, 2 p. 176

24/ CDIP 2, 2 p. 178

25/ CDIP 2, 2 p. 183

26/ CDIP 2, 2 p. 174

$27 /$ CDIP 2, 2 pp. 271. 272

28/ CDIP 2, 2 p. 278

29/ BUSA

30/ CDIP 2. 2 p. 469

31/ CDIP 2, 2 p. 489

32/ CDIP 2. 2 p. 493

33/ CDIP 2. 2 p. 503

34/ CDIP 2, 2 pp. $506-507$

35/ CDIP 2. 2 pp. $522-523$

36/ CDIP 2. 2 p. 593

$37 /$ CDIP 2, 2 p. 783

38/ CDIP 2. 2 p. 607

39/ CDIP 2, 2 pp. 637, 638: La "Relación de los reos aprisionados del exército de J. G. Thupa Amaro. . " incluye ade más de los apellidos, algunas cortas aclaraciones, que consideré como relativas a la jerarquía estamental, puesto que resulta imposible creer, que se agregara al apellido de cada preso un término aclarativo. según un criterio distinto, al tenido en cuenta con el prisionero precedente. Estos términos son los siguientes: Español, indio. español, español, cacique. . . mestizo, español, cacica. capitán, criado, e Ysabel Coya, caso en el cual, no hay aclaración adicional alguna, aunque el apellido indica que se trata de una noble, ya que el título quya se otorgaba a las mujeres casadas de la "familia" de los incas; más adelante se menciona a los esclavos.

40/ CDIP 2, 2 p. 660

41/ BUSA. He aquí, algo curioso: J. G.
Thupa Amaro declaró, que su "jurado real" había escrito: "Un Yqueño Español que estaba en Marcapata y a la verdad era Mestizo Blanco pelo rubio y ojos azules". El término "español" sólo tiene sentido. si designa a un noble, mientras que "mestizo blanco" se refiere a la casta o a la cultura.

421 CDIP 2, 3 p. 62

43/ CDIP 2, 2 p. 769

44/ CDIP 2, 2 p. 770

45/ CDIP 2, 2 p. 772

46/ CDIP 2, 2 pp. 818, 819

47/ CDIP 2, 1 p. 512

48/ CDIP 2. 4 p. 244

49/ CDIP 2, 3 p. 203

$50 /$ CDIP 2, 3 p. 267

$51 /$ JCB Pp. 458 - 459

521 CDIP 2, 1 p. 590

$53 /$ CDIP 2, 3 p. 366

54/ CDIP 2. 1 p. 366

55/ CDIP 2, 1 p. 337

$57 /$ CDIP 2. 1 p. 387

58/ CDIP 2, 1 p. 411

59/ CDIP 2, 1 p. 99

60/ CDIP 2, 1 p. 387

61/ CDIP 2, 1 p. 102

62/ CDIP 2, 1 p. 109

63/ CDIP 2, 1 p. 118

64/ CDIP 2, 1 p. 122

65/ CDIP 2, 1 p. 129

66/ CDIP 2, 1 p. 690

67/ CDIP 2, 1 p. 701

68/ CDIP 2, 1 p. 215

69/ CDIP 2, 1 p. 226

70/ CDIP 2. 1 pp. 426, 427

71/ CDIP 2, 1 p. 429

721 "Expediente sobre el presbítero don Augustín Valdés de Carabaya por haber seducido a varios indios que procedieron contra su cacique", 17 de febrero de 1789 . AHC, sección Historia, fich. 47, legajo 9-11. 


\section{TABLA 4}

\section{Contraposición}

indios: españoles

indios y cholos: españoles $y$ otros indios: criollos indios y mestizos: españoles indios: cholos indios: españoles y mestizos

americanos (o análogos): españoles
Número de casos

52

5

4

12

2

26

13

\section{Número de las citas}

$2-10,12-14,16-18$, $22,23,26,30,29,34$, $35,37-39,41,48,50$, $53,55-59,61-64,67$, $68,72-83$

$25,28,60,65,72$

$5,25,33,63$

$10,11,19,20,24,31$, $41,45,51,52,54,84$ 29,61

$1,15,19,20,21,27$, $32,33,36,37,40-47$, $49,60,60-71,85-87$

$5,12,29,30,33,36$, $51,63,64,66-68,71$

\section{FUENTES:}

$1 /$ CDIP 2, 1 pp. 9 - 10

2) CDIP 2, 1 p. 26

3/ CDIP 2, 2 p. 38

4/ CDIP 2, 2 p. 78

5/ CDIP 2, 2 pp. 151-152

6/ CDIP 2, 2 p. 178

7/ CDIP 2, 2 p. 197

8/ CDIP 2, 2 p. 241

9/ CDIP 2, 2 p. 244

10/ CDIP 2, 2 pp, 255, 307

11/ CDIP 2, 2 p. 347

12/ CDIP 2, 2 p. 352
13/ CDIP 2, 2 p. 357

14/ CDIP 2, 2 p. 398

15/ CDIP 2, 2 p. 394

16/ CDIP 2, 2 p. 407

17/ CDIP 2, 2 pp. $436-438$

18/ CDIP 2, 2 p. 408

19/ CDIP 2, 2 p. 426

20/ CDIP 2, 2 pp. $468-469$

21/ CDIP 2, 2 p. 470

22/ CDIP 2, 2 p. 471

23/ CDIP 2, 2 p. 485

24/ CDIP 2, 2 p. 497 
25/ CDIP 2, 2 p. 505

26/ CDIP 2, 2 p. 508

27/ CDIP 2, 2 p. 509

28/ CDIP 2, 2 pp. $508-510$

29/ CDIP 2, 2 p. 532

30/ CDIP 2, 2 p. 530

31/ CDIP 2, 3 pp. 51-54

32/ CDIP 2, 3 p. 56

33/ CDIP 2, 2 pp. $585-586$

34/ CDIP 2, 2 p. 592

35/ CDIP 2, 2 p. 594

36/ CDIP 2, 2 pp. $548-549$

$37 /$ CDIP 2, 2 pp. 826, 827

38/ CDIP 2, 2 p. 624

39/ CDIP 2, 2 p. 649

4(1)/ CDIP 2, 2 pp. 649-65()

41/ CDIP 2, 2 pp. 659-661)

42/ CDIP 2, 2 p. 711

43/ CDIP 2, 3 p. 62

44/ CDIP 2, 3 pp. $59-61$

45/ CDIP 2, 2 pp. $675-678$

46/ CDIP 2, 2 p. 680

47/ CDIP 2, 2 p. 685

48/ CDIP 2, 2 p. 683

49/ CDIP 2, 2 p. 755

50/ CDIP 2, 2 pp. 694-695

51/ CDIP 2, 2 p. 769

52/ CDIP 2, 2 pp. $765-766$

$53 /$ CDIP 2, 2 p. 782

54/ CDIP 2, 2 p. 781

55/ CDIP 2, 2 pp. $775-776$

56/ CDIP 2, 2 p. 801
57/ CDIP 2, 2 p. 807

58/ CDIP 2, 2 pp. $803-804$

59/ CDIP 2, 2 pp. $802-803$

60/ CDIP 2, 2 p. 814

61/ CDIP 2, 2 p. 815

62/ BL p. 819

63/ BL p. 817

64/ FAL pp. $140-158$

65/ FAL 140-158

66/ CDIP 2, 3 p. 29

67/ CDIP 2, 3 p. 131

68/ CDIP 2, 3 p. 127

69/ CDIP 2, 3 p. 172

70/ CDIP 2, 3 p. 144

71/ CDIP 2, 3 p. 167

72/ CDIP 2, 3 pp. $171-172$

73/ CDIP 2. 3 p. 176

74/ CDIP 2, 3 pp. $143-144$

75/ CDIP 2, 3 p. 219

76/ CDIP 2, 3 p. 139

77/ CDIP 2, 1 p. 397

78/ CDIP 2, 1 p. 336

79/ CDIP 2, 1 p. 338

80/ CDIP 2, 1 p. 341

81/ CDIP 2, 1 pp. $342-344$

82/ CDIP 2, 1 p. 359

$83 /$ CDIP 2, 1 pp. 363,366

84/ CDIP 2, 1 pp. $102-103$

85/ CDIP 2, 1 p. 112

86/ CDIP 2, 1 p. 113

87/ CDIP 2, 1 pp. $117-118$ 


\section{NOTAS}

Abreviaturas utilizadas:

CDIP Colección documental de la independencia del Perú, tomo II. Vol. 1-4, que son indicados así: CDIP 21, 1; CDIP 2, 2; CDIP 2, 3; CDIP 2, 4.

FAL Francisco A. LOAYZA. Preliminares del incendio. Documentos del año de 1776 a 1780 . en su mayoría inéditos, anteriores y sobre la Revolución Libertadora que engendró y dio vida José Gabriel Tupak Amaru, en 1780. Coordinzción, acotaciones, comentarios y notas breves por . . .. Lima 1947.

JCB Jorge CORNEJO Bouroncle, Túpac Amaru. La Revolución Precursora de la Emancipación Continental. Cusco 1963.

BUSA Biblioteca de la Universidad de San Antonio Abad del Cusco. en la cual se ha conservado inédito el manuscrito: "Extracto de las respuestas que dio a las preguntas que se le hicieron a el vil insurgente José Condorcanqui fingido Túpac Amaru y supuesto cacique de pueblos que no hera".

RAHC Revista del Archivo Histórico del Cusco.

AHC Archivo Histórico del Cusco.

BL Boleslao LEWIN, la rebelión de Túpac Amaru y los orígenes de la Independencia Hispanoamericana. por. ..., Buenos Aires, 1967.

VAV Víctor ANGLES Vargas, El Cacique Tambohuacso, Lima 1975.

GGR Guillermo GALDOS Rodríguez, La rebelión de los pasquines. Arequipa. 1967.

1/ Cfr. Jan SZEMINSKI, "La insurrección de Túpac Amaru II : ¿Guerra de independencia o revolución?". Estudios Latinoamericanos, vol. 2, pp. 13-25. Ossolineum 1974. O también: Alberto FLORES Galindo. Túpac Amaru II - 1780, antología, Lima 1976. Retablo de Papel Ediciones, pp. $199-259$.

21 CDIP 2.3 p. 172

3/ CDIP 2.2 p. 152
4/ CDIP 2. 2 p. 256

5/ CDIP 2, 2 p. 288

6/ CDIP 2, 2 p. 250

7/ CDIP 2, 2 p. 310

8/ CDIP 2, 2 p. 315

9/ CDIP 2. 2 p. 347

10/ CDIP 2, 2 p. 386

11/ CDIP 2, 2 p. 384

12/ CDIP 2, 2 p. 426

13/ CDIP 2, 2 p. 474

14/ CDIP 2, 2 p. 494

15/ CDIP 2, 2 p. 493

16/ CDIP 2, 2 p. 503

17/ CDIP 2, 2 p. 509

18/ CDIP 2. 2 p. 545

19/ CDIP 2, 2 p. 629

2u/ CDIP 2, 2 p. 766

21/ BUSA

22/ CDIP 2, 1 p. 495

23/ JCB p. 429

24/ CDIP 2, 3 p. 127

25/ La cuestión de las divisiones estamentales locales en el siglo XVIII, que eran la continuación de las divisiones prehispánicas. será ampliamente discutida en "Los objetivos de los tupamaristas. . . etc" (en prensa)

26/ CDIP 2, 2 p. 382

27/ CDIP 2, 2 p. 522

28/ CDIP 2, 2 p. 523

$29 /$ de la raíz "kura-", ser mayor

30/ Cfr. los capítulos II y III de "Los objetivos de los Tupamaristas. ... etc.", en prensa.

31/ CDIP 2, 2 p. 489

321 No he considerado aquí, dos variantes de la nobleza: Los títulos de nobleza españoles y el ser descendiente de los conquistadores, tanto los primeros, como lo segundo hacían de cada uno un noble. no siendo indispensables para establecer la terminología de la nobleza en el Perú. Tampoco he tenido en cuenta aquí, los particulares de la nobleza indígena, ya que son considerados más o menos en detalle en los capítulos II y III de "Los objetivos de los tupamaristas.... etc."

33/ BL p. $295-298$

34/ RAHC No. 12, 1967, p. 212

35/ VAV p. 143

36/ CDIP 2, 2 p. 259 


\section{$37 /$ BUSA \\ 38/ CDIP 2, 3 p. 129 \\ 39/ CDIP 2, 3 p. 131 \\ 40/ CDIP 2, 3 p. 191 \\ 41/ CDIP 2, 3 p. 144 \\ 42/ CDIP 2, 3 p. 145 \\ 43/ CDIP 2, 2 p. 602}

44/ Runa- ser humano, hombre, es hoy día etnónimo de la población que habla en quechua en el Perú y Bolivia. Algunas veces significa: Campesinos, gente, obreros. pueblo, en contraposición a misti, miembros de las clases altas, hispanizadas. Como se trata del empleo de una palabra que designa al ser humano creo, que su uso es bastante arcaico.

45/ CDIP 2. 3 p. 164

46/ Sullk'a - hermanos menores, lo que puede significar grupo inferior en la jerarquía.

$47 /$

CDIP 2, 3 p. 173

48/ CIDP 2, 2 p. 466

49/ CDIP 2, 1 p. 19

50/ CDIP 2.1 p. 21

51/ CDIP 2,1 p. 29

52/ CDIP 2, 1 p. 33

53/ CDIP 2, 2 p. 137

54/ CDIP 2, 2 pp. 143-146

55/ CDIP 2, 2 pp. $490-491$

56/ CDIP 2, 2 p. 503

$57 /$ CDIP 2. 2 p. 504

58/ CDIP 2, 2 p. 507

59/ CDIP 2. 2 p. 506

6ú/ CDIP 2. 2 p. 510

61/ CDIP 2, 2 p. 566

62/ CDIP 2. 2 p. 576

63/ CDIP 2. 2 p. 594

64/ CDIP 2, 2 p. 669

65/ CDIP 2. 2 p. 624

66/ CDIP 2.3 p. 313

67/ CDIP 2. 2 p. 660

68/ CDIP 2, 3 p. 213

69/ CDIP 2, 2 pp. $178-176$

70/ CDIP 2,1 p. 39

71/ CDIP 2, 1 p. 42

72/ CDIP 2, 1 p. 49

73/ VAV p. 146

74/ CDIP 2, 2 p. 176

75/ CDIP 2. 2 p. 426

76/ CDIP 2, 1 p. 363

77/ CDIP 2, 1 p. 366

78/ CDIP 2. 1 p. 426

79/ CDIP 2.1 p. 430

80/ CDIP 2,1 p. 195

$81 /$ CDIP 2, 2 pp. $802-803$
821 CDIP 2, 2 p. 806

83/ CDIP 2, 2 p. 505

84/ CDIP 2, 2 pp. $669-671$

85/ CDIP 2, 1 p. 16

86/ CDIP 2, 1 p. 21

87/ CDIP 2, 2 p. 79

88/ CDIP 2, 2 pp. $156-157$

89/ BUSA

90/ CDIP 2, 2 p. 462

91/ CDIP 2, 2 p. 530

921 CDIP 2, 2 p. 592

93/ JCB pp. $426-431$

94/ E.g. cfr. CDIP 2, 2 p. 594; 5 de mayo de 1790, Cusco, "Expediente sobre que se informe a S.M. los méritos y servicios prestados por el reverendo padre fray Miguel Lizárraga, de la orden de predicadores". AHC, paquete 5, legajo 12,13, años 1790-1791, fichas 67-87, Arch. Cort. Sec. Historia Fich. 70. CDIP 2, 3 p. 523.

95/ Cfr. la tabla 4

96/ CDIP 2, 3 p. 19

97/ CDIP 2, 1 p. 343

98/ CDIP 2, 1 p. 452

99/ CDIP 2, 1 pp. $125-126$

100/ Cfr. GGR p. 73. Es ésta una discusión detallada del desarrollo de los acontecimientos de Arequipa en los años 1779 1780. El autor sostiene, que la llamada rebelión de los pasquines, en la cual participó ante todo la plebe de Arequipa, era independentista $y$ por sus objetivos cercana a la insurrección de J. G. Thupa Amaro. Durante una conversación que sostuve con el autor, en el mes de octubre de 1974 en Arequipa, dijo estar convencido de que el nombre Casimiro era $y$ es aún utilizado como sinónimo de cualquier indio.

$101 /$ CDIP 2, 2 p. 272

102/ CDIP 2, 1 p. 406

103/ CDIP 2, 2 p. 346

104/ CDIP 2, 2 p. 530

$105 /$ CDIP 2, 2 p. 292

$106 /$ CDIP 2, 2 pp. 769,770

$107 /$ CDIP 2, 2 p. 272

108/ Cfr. los capítulos II y III de "Los objetivos de los tupamaristas. .."

109/ CDIP 2, 2 p. 772

$110 /$ Cfr. los capítulos II y III de "Los objetivos de los tupamaristas. .."

111/ CDIP 2, 2 p. 255

$112 /$ CDIP 2, 1 p. 49

113/ CDIP 2, 1 p. 162

114/ CDIP 2, 2 p. 674

$115 /$ CDIP 2, 1 p. 345 